
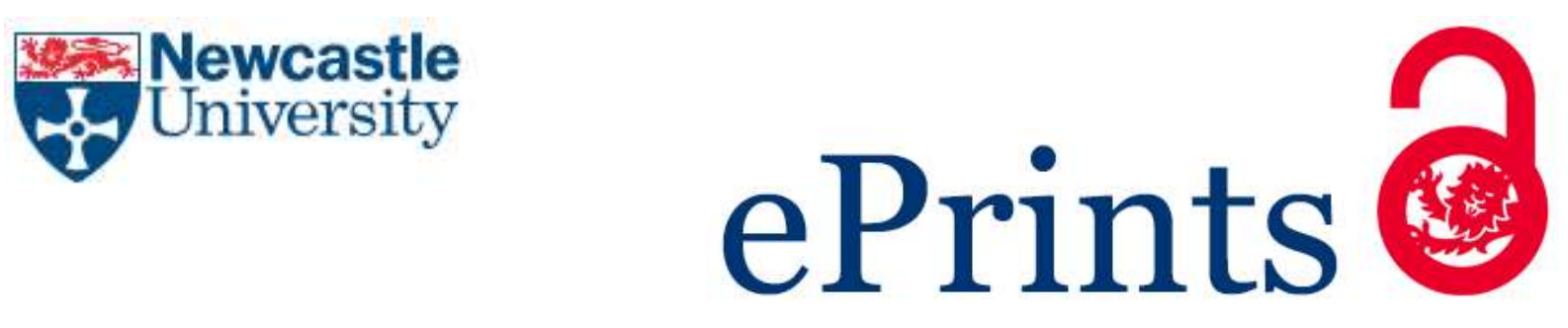

Korkmaz C, Cansu DU, Sayer JA. Urolithiasis as an extraarticular manifestation of ankylosing spondylitis. Rheumatology International 2017, 37(12), 1949-1956.

\title{
Copyright:
}

The final publication is available at Springer via https://doi.org/10.1007/s00296-017-3788-0

DOI link to article:

Date deposited:

$11 / 01 / 2018$

Embargo release date:

18 August 2018

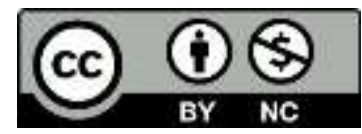

This work is licensed under a Creative Commons Attribution-NonCommercial 3.0 Unported License 


\section{UROLITHIASIS AS AN EXTRA-ARTICULAR MANIFESTATION OF ANKYLOSING SPONDYLITIS}

Cengiz KORKMAZ, MD, Professor in Rheumatology, Eskişehir Osmangazi University, Department of Internal Medicine, Division of Rheumatology, Eskişehir, TURKEY.

Döndü Üsküdar Cansu, MD, Assoc. Professor in Rheumatology, Eskişehir Osmangazi University, Department of Internal Medicine, Division of Rheumatology, Eskişehir, TURKEY.

John A Sayer, MD PhD, Professor of Renal Medicine, Institute of Genetic Medicine, Newcastle University, United Kingdom.

Correspondence to Cengiz KORKMAZ, Osmangazi University, Department of Internal Medicine, Division of Rheumatology, Eskişehir, 26480, TURKEY.

Tel: +90 $2222392979-2926$

E mail: ckorkmaz@ogu.edu.tr 


\title{
UROLITHIASIS AS AN EXTRAARTICULAR MANIFESTATION OF ANKYLOSING SPONDYLITIS
}

\begin{abstract}
Ankylosing spondylitis (AS) affects sacroiliac and axial joints, as well as extraarticular organs such as the eye, lung, bowel and heart. Although examples of renal involvement in AS such as IgA nephropathy, amyloidosis and glomerulonephritis have been reported, it has not been emphasized that urolithiasis is frequently formed in the course of AS. Growing evidence indicates that urolithiasis can be observed in AS patients and is more frequent than some other extraarticular involvements. In this review, we will discuss frequency and predictors of ASrelated urolithiasis and summarize the possible underlying genetic and biochemical mechanisms. We believe an increased awareness of urolithiasis as a complication of AS will encourage future studies that will shed light on disease mechanisms and preventative therapies.
\end{abstract}

Key Words: Ankylosing spondylitis, urolithiasis, nephrolithiasis, renal stone, bone, intestinal inflammation.

\section{INTRODUCTION}

Ankylosing spondylitis (AS) is a chronic inflammatory disease characterized by sacroiliac and axial joints inflammation [1,2]. It is 2-3 times more frequent among men, and its prevalence is between 0.2-1.2\% [3]. Extra-articular manifestations may arise in AS as a result of uncontrolled inflammation [4]. Anterior uveitis is one of the most common among these. Other examples include inflammation of the aortic root, which may lead to aortic valve insufficiency and conduction problems in the heart. Extraarticular manifestations also include apical pulmonary fibrosis, inflammatory bowel disease, nonspecific colitis, and psoriasis [4]. The frequency of renal abnormalities has been reported to be between 10-35\%, and includes 
glomerulonephritis, $\operatorname{Ig}$ A nephropathy, microscopic or macroscopic hematuria, and amyloidosis [3]. However, none of those studies mentioned urolithiasis as a feature of AS. More recently, several studies have shown that urolithiasis is indeed frequently observed among patients with AS [5-7]. Since urolithiasis may have a relapsing nature and may necessitate surgical intervention [8], it may cause significant morbidity beyond the morbidity caused by AS alone._Furthermore, urolithiasis can cause chronic kidney disease or urinary system infections and obstruction. In this regard, clinicians should be aware of ASrelated urolithiasis. In this review, we will examine the literature related to urolithiasis as an extraarticular sign of AS, and discuss possible biochemical and genetic factors in its pathogenesis. We searched Pub Med, MEDLINE, EMBASE, Scopus and Web of Science for sources using keywords: ankylosing spondylitis, urolithiasis, nephrolithiasis, renal stone, kidney stone, calcium oxalate, ANKH gene, inflammatory bowel disease, Crohn's disease, ulcerative colitis, bone, hypopyrophosphaturia. We also checked the references list of relevant studies to identify additional studies. We included studies investigating frequency of urolithiasis in AS; lithogenic and antilithogenic factors responsible for renal stone formation in AS or inflammatory bowel diseases; ANKH gene......

\section{THE EVIDENCE FOR UROLITHIASIS IN ANKYLOSING SPONDYLITIS}

In 1972, Elian et al. reported that $13.6 \%$ of AS patients (Table 1) had urolithiasis [9]. They proposed that limited spinal mobility and altered pyelo-pelvic position might be an underlying predisposing factor for urolithiasis. In 1973, Mladevoniç reported that $8.5 \%$ of AS patients had kidney stones [10] compared to a reported, frequency of kidney stones of $1.9 \%$ among the general population of Croatia. It was also proposed that spinal ankylosis and hip joint involvement were risk factors for stone formation. In 1989, Jimenes Balderas et al. detected urolithiasis in $25 \%$ of AS patients. Researchers also reported hyperuricemia in 5 of these 23 patients [11].

Based on our observation during our routine clinical practice that some of our patients with AS had recurrent urolithiasis, we conducted an ultrasonography (USG) based study in 2005 [5]. We showed presence of urolithiasis in 20 (24\%) of 83 AS patients.

In 2006, Incel et al. from Turkey found $11.3 \%$ of AS patients had urolithiasis, however, this rate was not different in comparison to healthy controls. They found that both lumbar and femoral neck bone mineral densities (BMD) were lower among AS patients with urolithiasis 
and proposed a possible relationship between osteoporosis, urolithiasis and femoral neck fracture [12].

In 2006, Canales et al. evaluated the frequency of kidney stone among patients with spondyloarthropathy ( $\mathrm{SpA}$ ) including patients with $\mathrm{AS}$, and compared the results to that of patients with rheumatoid arthritis (RA). The frequency of self-reported kidney stone was $29.11 \%$ among patients with SPA and $12.5 \%$ among patients with RA [13].

In their 2011 study with 102 AS patients, Cansu et al. investigated possible predictors of radiographic and functional disability, and they detected urolithiasis in $27.5 \%$ of patients with AS [14].

In 2012, Lui et al. found 7.5\% of 504 AS patients had urolithiasis, and they reported that patients with renal stones had worse functional indices compared to patients without stone. Additionally, the frequency of peripheral arthritis and requirement for biological drugs were found to be greater among patients with urolithiasis. They also stated that diseases like diabetes and Crohn's disease may have contributed to stone formation in these patients. The researchers could not find an association between presence of syndesmophytes and urolithiasis [15].

In 2012, Fallahi et al. found the frequency of urolithiasis among 163 Iranian patients with AS was $11.7 \%$, in comparison to $5.7 \%$ in 7649 normal controls. They found higher values of Bath ankylosing spondylitis metrology index (BASMI), Bath ankylosing spondylitis functional index (BASFI) and Bath ankylosing spondylitis disease activity index (BASDAI) parameters in patients with kidney stone [16].

In their 2014 prospective, population based nation-wide study from Sweeden, Jakobsen et al. investigated frequency of kidney stone and its predictors in 8572 AS patients that were cohort against 39639 healthy individuals. The two groups were evaluated for comorbid diseases. At the beginning of the study, frequency of urolithiasis was $1.6 \%$ among AS patients and $0.7 \%$ in the control group. At the end of the study, these rates were $4 \%$ and $1.8 \%$, respectively. They found the unadjusted Hazard Ratios of urolithiasis for AS compared to population comparators as 2.4 (95\% CI 2.1 to 2.9$)$. In that same study, male sex, inflammatory bowel disease, history of previous urolithiasis, disease severity and utilization of anti-tumor necrosis factor (TNF) medication were found as predictors for urolithiasis. Even after necessary 
adjustments for age, inflammatory bowel disease, history of previous urolithiasis, AS was found to be a risk factor for urolithiasis $(2.1$ (95\%CI 1.8-2.4) [8].

In a 2015 study from Turkey, Resorlu et al. compared 38 AS patients and 38 healthy controls in terms of frequency of kidney stone. They found urolithiasis was present among $18.4 \%$ of AS patients and $10.4 \%$ of controls [17].

Most of these studies were conducted in centers that provided tertiary health care services and therefore are hampered by both selection and referral bias. Many of the studies included very small patient numbers. However, the Swedish cohort study included a large database making it less prone to bias and providing more robust statistical evidence. Based on these data, urolithiasis appears to be 2.5 times more frequent among AS patients in comparison to the general population.

\section{Clinical Predictors for Urolithiasis in AS Patients}

Previous studies have suggested that hip joint involvement and spinal ankyloses in AS are risk factors for stone formation [9, 10]. In our study, urolithiasis was associated with advanced age, longer disease duration [5]. Additionally, there are studies that found association between urolithiasis and functional and radiological severity, and male sex. The Swedish study suggests that previous history of urolithiasis, presence of inflammatory bowel disease and treatment with anti-TNF alpha are predictors for urolithiasis. Taken together, these studies do not provide a homogenous list of predictors for urolithiasis related with AS, and this may be due to differences in their designs, limitations in patient numbers and variations in ethnicities of study populations.

\section{Possible mechanism(s) for the development of urolithiasis}

The balance between lithogenic and antilithogenic factors is important for renal stone formation. Urolithiasis may be secondary to multiple underlying factors with a range underlying disease and complex mechanisms involving kidney, intestine and bone predisposing to disease [18]. Bone remodelling and intestinal changes in the course of AS may change this balance to lithogenic side (Figure 1). Important antilithogenic factors include urinary citrate and magnesium. Hypercalciuria, hyperoxaluria, hyperuricemia, reduced urinary flow and dehydration are all lithogenic factors $[18,19]$. In AS, these conditions may be the consequence of a wide variety of diseases causing disturbances in intestinal absorption, renal resorption and bone remodelling. 


\section{The possible role of gastrointestinal system}

Recognition of the type of the stone may shed light on its pathogenesis; however, our knowledge about the stone types in AS is limited. The most common type of kidney stones observed in the general population is calcium oxalate $(\mathrm{CaOx})$. For formation of $\mathrm{CaOx}$ stones, hypercalciuria and hyperoxaluria are the most common biochemical risk factors [18]. Urolithiasis is also known to be frequent (10.5\%) among patients with Crohn's disease [20], an inflammatory bowel diseases. The majority of the stones found in Crohn's disease are also $\mathrm{CaOx}$ stones [20]. The pathogenesis of urolithiasis occurring in Crohn's disease involves saponification of calcium with lipids inside the gut lumen and thereby, reduced calcium available for binding with oxalate, which is necessary to reduce absorption of oxalate from the bowel. Thus, intestinal oxalate absorption is increased, and this leads to hyperoxaluria and is a risk factor for stone formation in kidneys. It has not been proven that the same mechanism is also responsible for urolithiasis in AS, but it is likely that it may be one of the factors playing role in development of AS-related urolithiasis. A reciprocal clinical and genetic overlap exist between inflammatory bowel disease and AS. For instance, subclinical colitis is present in $2 / 3$ of AS patients [21]. Intestinal biopsy examinations show that $26 \%$ of AS patients demonstrate a histological appearance similar to what is seen in Crohn's disease, and $10 \%$ of the patients are diagnosed with inflammatory bowel disease [22, 23]. Genetic factors common to AS and inflammatory bowel diseases may have a role in this process. For example, HLA-B27 positivity has been reported with the rates of $85 \%$ and $33 \%$ in AS and inflammatory bowel diseases, respectively [23]. IL23R gene has been shown to be associated with AS and inflammatory bowel diseases [24,25]. van Sommeren et al. showed that AS patients have the largest number of risk loci that are shared with inflammatory bowel disease [26]. Recently calprotectin, which is an indicator of intestinal inflammation, has been shown to be elevated in serum and faeces of patients with AS, and it has been associated with radiological severity and other inflammatory parameters [27,28]. Calprotectin is especially important for showing macrophage-neutrophil infiltration in inflammatory bowel diseases [29]. Elevated levels of calprotectin in AS suggests possible role of intestinal inflammation in pathogenesis of AS. Also, antibodies against commensal bacteria have been detected in patients with AS [30], as well as in inflammatory bowel diseases. The most important of these antibodies is antiflagellin, whose titer has been found to be correlated with increased acute phase response in AS [30]. Flagellin is a molecular component on bacterial surface, and interacts with TLR5 and induces production of proinflammatory cytokines. Another 
interesting finding was that Gönüllü et al. found higher blood IgA levels in AS patients with urolithiasis compared to the AS patients who did not have urolithiasis [31]. However, we do not know whether there is a causal relationship between IgA and urolithiasis in AS patients. Shodjai-Moradi et al. found that the levels of IgA were significantly elevated in patients with active AS compared with patients with inactive AS or RA, or with healthy controls [32]. Other studies have also reported similar results in patients with AS and compared with patients with RA[33,34]. It has been reported that there is an association between increased AS disease activity and increased serum IgA levels [35]. Ardicoğlu et al suggested that the increase in IgA levels is a sign of an enterobacterial antigenic stimulation that occurs in the gastrointestinal tract during the active phase of the disease [36]. It is tempting to speculate that enterobacterial antigenic stimulation and subclinical colitis might lead to increase in the levels of $\operatorname{IgA}$ and hyperoxaluria. We believe that the possible relationship between $\operatorname{IgA}$, urolithiasis and enterobacterial stimulation seems to be open to further investigations.

We hypothesize that one of the mechanisms responsible for development of urolithiasis in AS may be intestinal inflammation occurring during the course of AS, resulting in enteric hyperoxaluria. However, it will be necessary to know whether patients with and without kidney stones differ in terms of presence of intestinal inflammation and hyperoxaluria.

\section{The role of Bone}

Bone structure is compromised by AS, as the disease causes both new bone formation (ankylosis, syndesmophytes), and leads to osteoporosis and fractures of the trabecular structure of the vertebral column [37]. Factors playing a role in the development of osteoporosis in AS include systemic inflammation, vitamin D deficiency, inappropriate load on bones due to abnormal gait and posture, malabsorption, inflammatory bowel disease and low body mass index [38]. İncel et al. found an association between femoral neck osteoporosis and urolithiasis. The authors proposed that development of urolithiasis and osteoporosis might be separate outcomes that stem from a common mechanism [12]. In line with this suggestion, some studies have illuminated the osteoporotic fractures develop more frequently in patients with urolithiasis than in the general popuation [39].

Levels of the bone turnover markers RANK-RANK-L, DKK-1, sclerostin and osteoprotegerin are altered during this process [40,41]. RANK-RANK-L is activated by inflammatory cytokines, and it leads to resorption. Osteoprotegerin, on the other hand, has an 
antiresorptive role. In AS patients, low levels of osteoprotegerin have been detected together with high sRANKL/OPG ratios [42]. It is obviously important to know how the calcium levels change during this bone turnover within the bone structure which holds $99 \%$ of the body calcium. It has been reported that inflammatory cytokines such as IL-6, IL-1, TNF-alpha not only play a role in the inflammatory process of AS, but are involved in the osteoporosis of AS [43,44]. It is well known that TNF-alpha and IL-1 are among the most powerful stimulators of bone resorption and are well-recognised inhibitors of bone formation [45]. They may also result in hypercalciuria [46]. Taken together, hypercalciuria may be expected in AS patients due to both immobilization and inflammatory cytokines. There are conflicting studies as to whether or not hypercalciuria is prevalent in patients with AS [45]. In our 2006 study, although urinary calcium levels were increased in AS patients with urolithiasis, the difference was not statistically significant; nonetheless, frequency of hypercalciuria was higher among AS patients with urolithiasis compared to AS patients without urolithiasis [5]. In another study, serum calcium level was found higher among AS patients with urolithiasis [31]. As a conclusion, due to the limited number of urine analysis studies related with lithogenic and antilithogenic factors playing role in stone formation, and also because these studies were cross-sectional rather than involving serial analyses, it is unfortunately difficult to reach a definitive conclusion. Nonetheless, it can be said that both blood calcium levels and urinary calcium excretion are increased in some patients, which may contribute to the stone formation.

\section{Genes and urolithiasis in AS}

Environmental and genetic factors play important roles for development of urolithiasis. Those with a family history of urolithiasis have a higher risk [47]. Several recent studies have reported a positive family history and heritability in patients with urolithiasis [48-50]. This finding indicates to the importance of genetic factors. However, there are no studies which have proven a genetic risk factor in patients with AS-related urolithiasis. However, ANKH has been proposed as a genetic marker in AS pathogenesis [51-53], as well as a possible contributor to the stone formation [54]. ANKH encodes ANK is a transmembrane transporter protein which serves to transport intracellular pyrophosphate out of the cell, and thus maintain a balance in inorganic pyrophosphate (PYP) levels [55]. Mutations in ANKH result in chondrocalcinosis and craniometaphyseal dysplasias. In addition, functional loss that develops as a result of the mutations in ANKH leads to the arthritic process, new bone 
formations and ankylosis that are characteristics of AS [55]. Normally, inorganic pyrophosphate inhibits calcification [56] and pyrophosphate presents in urine and prevents formation of apatite crystals [57]. Hypopyrophosphaturia is therefore a risk factor for urolithiasis [58]. Considering a possible role of ANKH in development of urolithiasis, we analyzed 6 single nucleotide polymorphisms within ANKH in 23 patients with AS [54] but did not find any association between ANKH polymorphism and renal stones.

$A N K H$ has also significance in terms of AS. Tsui et al. reported 5-Flanking region of $A N K H$ to be a novel genetic marker for AS [51]. The same researchers showed that while two intronic markers at the $3^{\prime}$ end of $A N K H$ gene were associated with AS in males, two intronic markers at 5'end of this gene were associated with AS in females [52]. Liu et al also showed that variation in $A N K H$ influences susceptibility to AS in Chinese patients [53]. However, no significant relationship between gender and $A N K H$ gene was identified in this study. On the other hand, Pimentel Santos et al., and Timms et al. stated that ANKH was not associated with AS, and had no effect on the severity of the disease [59,60]. Differences in these study results may have arisen from different ethnicities of the study populations, variations in case definitions, and differences in analytical methods for detection of $A N K H$ marker variants. In summary, ANKH gene polymorphism deserves further research, which may yield interesting results with regards to its possible roles in AS pathogenesis and stone formation.

\section{TREATMENT DRUGS AND UROLITHIASIS}

Drug-induced urolithiasis has a prevalence of $0.44 \%(0.59 \%$ in women and $0.37 \%$ in men) [61]. Sulfasalazine is one of drugs that induce stone formation. Acetylsulfapyridine is a metabolite of sulfasalazine (SSZ), which is usually used for peripheral arthritis seen in the course of SpA including AS. SSZ is also used in patients with RA, inflammatory bowel diseases and juvenile chronic arthritis. In the literature, the development of urolithiasis due to SSZ use has been reported in patients with psoriatic arthritis [62], juvenile chronic arthritis [63] and ulcerative colitis [64]. Although the renal stone formation stemming from acetylsulfapyridine was confirmed by reflectance infrared spectroscopy and gas chromatography-mass spectrometry in some case reports [65], it is not clear whether urolithiasis results from SSZ or disease itself. It has been reported that there was no concrete association between SSZ use and renal stone formation in AS patients [5]. Further studies are needed to elucidate the potential role of SSZ on urolithiasis. Other medications that are used in the treatment of AS are nonsteroidal anti-inflammatory drugs (NSAIDs) and anti-TNF- 
alpha agents. In the literature, there are no conclusive data implicating anti-TNF-alpha agents and NSAIDs as contributors to renal stone formation in AS. However, it has been reported that NSAIDs may lead to papillary necrosis and sometimes mimics staghorn calculi [66].

\section{Clinical importance of urolithiasis}

As a chronic disease, AS impairs life quality, increases morbidity and mortality, and increases health costs [67]. Patients with AS-associated urolithiasis have higher recurrence rates in comparison to cases of urolithiasis among the general population [8]. In one of our studies, among 23 patients with urolithiasis, 10 patients experienced only single attack of urolithiasis, whereas 13 patients had history of multiple attacks [54]. Another interesting feature of ASassociated urolithiasis is that requirement for surgical intervention is 3 times more frequent in comparison to urolithiasis seen in the general population [54]. This is somewhat related to the more complicated course seen in AS-associated urolithiasis. In the study by Jakopsen et al., extracorporeal shock wave lithotripsy (ESWL was performed in $64 \%$ of patients, ureteroscopic procedures was performed in $25 \%$, surgical intervention was performed in $2 \%$, percutaneous nephrolithotomy was performed in $6 \%$, and retrograde intrarenal surgery was performed in $3 \%$ of their patients. Predictors of surgical requirement include previous urolithiasis, advanced age and atherosclerotic heart disease. Requirement of surgical intervention in the presence of atherosclerotic disease further increases the complexity of these cases.

Another downside of AS-related urolithiasis is that it can cause pyelonephritis. Unfortunately, there is no data from AS patients on this subject. However, 4-23\% of patients with Crohn'sassociated urolithiasis develop pyelonephritis [68,69]. This rate is 10-100 times higher compared to the general population [70]. Some patients with AS receive anti-TNF treatment, and this makes them more susceptible to such complications. Recurrent renal stone formations and repeated pyelonephritis attacks may lead to chronic kidney disease (CKD) [71]. Vupputuri et al. reported that the likelihood of CKD was 2-fold higher among persons with history of urolithiasis [72]. Another potential risk factor for CKD in case of urolithiasis is percutaneous nephrolithotomy. Following this procedure, $16.4 \%$ of patients may develop disturbance of renal functions [73]. Therefore, both the adverse effects of the stones on kidneys, and interventions aimed to treat them pose threat to the renal functions.

\section{FUTURE IMPLICATIONS AND CONCLUSIONS}


Urolithiasis is an extra-articular manifestations of AS. There is limited data concerning the frequency of urolithiasis, which may be because of the little awareness on this subject. Increasing awareness would trigger future studies on this topic, which would help us better understand the ethnic and environmental factors that play role in development of urolithiasis. According to the limited data at hand, urolithiasis has the potential of increasing morbidity and mortality of the disease. For this reason, studies related with the mechanisms involved in development of stones are necessary. Stone formation may be attributed to multiple mechanisms. Combined effects of bone resorption caused by inflammatory cytokines and immobilization and possible hypercalciuria, increased oxalate absorption and hyperoxaluria resulting from intestinal inflammation, and genetic factors related with stone formation may create tendency towards urolithiasis. Research aimed at these mechanisms would enlighten this topic and offer necessary measures for prevention. Further studies including repeated 24h urinary sampling analysing lithogenic and antilithogenic factors in urine in AS patients with and without a history of urolithiasis, as well as analysis of stone composition in AS patients, are expected to give further indications to the pathogenesis involved in Stone formation in AS patients.

Funding: No specific funding was received from and bodies.

Disclosure statement: We have no conflict of interest to declare.

\section{REFERENCES}

1-Van der Heijde D. Ankylosing spondylitis. In: Klippel JH, Stone JH, Crofford LJ, White PH (eds) Primer on the rheumatic disease $13^{\text {th }}$ edn. Springer, Berlin. 
2- Sieper J, Braun J, Rudwaleit M, Boonen A, Zink A. (2002) Ankylosing spondylitis: an overview. Ann Rheum Dis. 61 (Suppl 3):iii8-18.

3- El Maghraoui A. (2011) Extra-articular manifestations of ankylosing spondylitis: prevalence, characteristics and therapeutic implications. Eur J Intern Med. 22:554-60.

4- Elewaut D, Matucci-Cerinic M. (2009) Treatment of ankylosing spondylitis and extraarticular manifestations in everyday rheumatology practice. Rheumatology (Oxford). 48:1029-35.

5-Korkmaz C, Ozcan A, Akçar N. (2005) Increased frequency of ultrasonographic findings suggestive of renal stones in patients with ankylosing spondylitis.Clin Exp Rheumatol. 23:389-92.

6-Jakobsen AK, Jacobsson LT, Patschan O, Askling J, Kristensen LE. (2014) Is nephrolithiasis an unrecognized extra-articular manifestation in ankylosing spondylitis? A prospective population-based Swedish national cohort study with matched general population comparator subjects. PLoS One 25;9:

7-Lui NL, Carty A, Haroon N, Shen H, Cook RJ, Inman RD. (2011) Clinical correlates of urolithiasis in ankylosing spondylitis. J Rheumatol. 38:1953-6.

8- Jakobsen AK, Jacobsson LT, Patschan O, Hopfgarten T, Askling J, Kristensen LE. (2015) Surgical interventions for nephrolithiasis in ankylosing spondylitis and the general population. Scand J Urol. 21:1-6

9-Elian N, Berinde L, Georgescu L, Ocica I, Saba I. (1972) Nephro-uropathic manifestations in ankylopoietic spondylitis. Med Interna (Bucur) 24:187-193.

10-Mladenovic V. (1973) Nephrolithiasis in ankylosing spondylitis. Rheumatizam 20:106110 (article in Croation).

11-Jimenez Balderas FJ, Robles EJ, Juan L, Badui E, Arellano H, Espinosa Said L, et al. (1989) Purine metabolism in ankylosing spondylitis: clinical study. Arch Invest Med (Mex) 20:163-170.

12-Incel NA, Gökoğlu F, Nacir B, İncel N. (2006) Bone and stone in ankylosing spondylitis: osteoporosis and urolithiasis. Clin Rheumatol 25:667-670.

13-Canales BK, Leonard SM, Singh JA, Orzano IM, Zimmermann B, Weiland D, et al. (2006) Spondyloarthropathy. An independent risk factor for kidney stones. J Endourol 20:542-546. 
14-Cansu DU, Calışır C, Savaş Yavaş U, Kaşifoğlu T, Korkmaz C. (2011) Predictors of radiographic severity and functional disability in Turkish patients with ankylosing spondylitis. Clin Rheumatol. 30:557-62.

15- Lui NL, Carty A, Haroon N, Shen H, Cook RJ, Inman RD. (2011) Clinical correlates of urolithiasis in ankylosing spondylitis. J Rheumatol. 38:1953-6.

16- Fallahi S, Jamshidi AR, Gharibdoost F, Mahmoudi M, Paragomi P, Nicknam MH, et al. (2012) Urolithiasis in ankylosing spondylitis:Correlation with BASDAI, BASFI and BASMI. Caspian J Intern Med 3:508-513

17-Resorlu H, Adam G, Aylanc N, Akbal A,Ozdemir H. (2015) Prospective evaluation of the renal morphology and vascular resistance inpatients with ankylosing spondylitis. Med Ultrason. 17:180-4.

18-Moe OW. (2006) Kidney Stones: pathophysiology and medical management. Lancet 367 (9507):333-344.

19-Sakhaee K, Maalouf NM, Sinnott B. (2012) Kiney Stones 2012:pathogenesis, diagnosis, and management. J Clin Endocrinol Metab 97:1847-1860.

20- Gaspar SR, Mendonça T, Oliveira P, Oliveira T, Dias J, Lopes T. (2016)

Urolithiasis and crohn's disease. Urol Ann. 8:297-304

21- Mielants H, Veys EM, Goemaere S, Goethals K, Cuvelier C, De Vos M. (1991)

Gut inflammation in the spondyloarthropathies: clinical, radiologic, biologic and genetic features in relation to the type of histology. A prospective study. J Rheumatol. 18:1542-51.

22-Pang SW, Davis JC: (2006) Clinical aspects of ankylosing spondylitis. In Ankylosing spondylitis and spondyloarthropathies 1st edition, Edited by: Weisman MH, Reveille JD, Van der Heijde D. Philadelphia: Mosby; 145-153

23-Mielants H, Bosch F van den: (2006) Inflammatory bowel disease spondyloarthritis: epidemiology, clinical features, and treatment. In Ankylosing spondylitis and spondyloarthropathies 1st edition, Edited by: Weisman MH, Reveille JD, Van der Heijde D. Philadelphia: Mosby; 65-74.

24- Duerr RH, Taylor KD, Brant SR, Rioux JD, Silverberg MS, Daly MJ, et al. (2006) A genome-wide association study identifies IL23R as an inflammatory bowel disease gene. Science. 1;314(5804):1461-3.

25- Rahman P, Inman RD, Gladman DD, Reeve JP, Peddle L, Maksymowych WP. (2008) Association of interleukin-23 receptor variants with ankylosing spondylitis. 
Arthritis Rheum. 58:1020-1025.

26- van Sommeren S, Janse M, Karjalainen J, Fehrmann R, Franke L, Fu J, Weersma RK. (2014) Extraintestinal manifestations and complications in inflammatory bowel disease: from sharedgenetics to shared biological pathways. Inflamm Bowel Dis. 20:987-94 27- Turina MC, Sieper J, Yeremenko N, Conrad K, Haibel H, Rudwaleit M, et.al. (2014) Calprotectin serum level is an independent marker for radiographic spinal progression in axial spondyloarthritis. Ann Rheum Dis. 73:1746-8

28- Matzkies FG, Targan SR, Berel D, Landers CJ, Reveille JD, McGovern DP, et al. (2012) Markers of intestinal inflammation in patients with ankylosing spondylitis: a pilot study.Arthritis Res Ther. 29;14(6):R261.

29- Foell D, Kucharzik T, Kraft M, Vogl T, Sorg C, Domschke W, Roth J. (2003) Neutrophil derived human S100A12 (EN-RAGE) is strongly expressed during chronic active inflammatory bowel disease. Gut. 52:847-53

30- Targan SR, Landers CJ, Yang H, Lodes MJ, Cong Y, Papadakis KA, et al. (2005) Antibodies to CBir1 flagellin define a unique response that is associated independently with complicated Crohn's disease. Gastroenterology. 128:2020-8

31- Gönüllü E, Bilge NŞ, Cansu DU, Bekmez M, Musmul A, Akçar N, et al. (2016) Risk factors for urolithiasis in patients with ankylosing spondylitis: a prospective case-control study. Urolithiasis. DOI:10.1007/s00240-016-0911-8

32-Shodjai-Moradi E, Ebringer A, Abuljadayel I: (1992) IgA antibody response to Klebsiella in ankylosing spondylitis measured by immunoblotting. Ann Rheum Dis 51: 233 - 237.

33- Khalafpour S, Ebringer A, Abuljadayel I, et al: (1988) Antibodies to Klebsiella and Proteus microorganisms in ankylosing spondytitis and rheumatoid arthritis patients measured by ELISA. Br J Rheumatol 27(suppl 2): $86-89$.

34-Yuan GH, Shi GY, Ding YZ: (1993) Antibodies to Klebsiella pneumoniae in ankylosing spondylitis. Zhonghua Nei Ka Za Zhi 32: 467 - 469 [in Chinese, English abstract].

35-Veys EM, van Laera M: (1973) Serum IgG, IgM, and IgA levels in ankylosing spondylitis. Ann Rheum Dis 32: 493 - 496.

36- Ardiçoğlu O, Atay MB, Ataoğlu H, et al. (1996) IgA antibodies to Klebsiella in ankylosing spondylitis. Clin Rheumatol 15: 573 - 576.

37- Muñoz-Ortego J, Vestergaard P, Rubio JB, Wordsworth P, Judge A, Javaid MK, et al. (2014) Ankylosing spondylitis is associated with an increased risk of vertebral and nonvertebral clinical fractures: a population-based cohort study. J Bone Miner Res. 29:1770-6 
38-Maghraoui AE. (2004) Osteoporosis and ankylosing spondylitis. Joint Bone Spine 71:291295.

39-Ou SM, Chen YT, Shih CJ, Tarng DC. (2015) Increased risk of bone fracture among patients with urinary calculi: a nationwide longitudinal population-based study. Osteoporos Int 26:1261-1269.

40-Klingberg E, Nurkkala M, Carlsten H, Forsblad-d'Elia H. (2014) Biomarkers of bone metabolism in ankylosing spondylitis in relation to osteoproliferation and osteoporosis. $\mathbf{J}$ Rheumatol 41:1349-1356.

41- Appel H, Ruiz-Heiland G, Listing J, Zwerina J, Herrmann M, Mueller R, et al. (2009) Altered skeletal expression of sclerostin and its link to radiographic progression in ankylosing spondylitis. Arthritis Rheum. 60:3257-62.

42- Saad CG, Ribeiro AC, Moraes JC, Takayama L, Goncalves CR, Rodrigues MB, de Oliveira RM, Silva CA, Bonfa E, Pereira RM. (2012) Low sclerostin levels: a predictive marker of persistent inflammation in ankylosing spondylitis during anti-tumor necrosis factor therapy? Arthritis Res Ther. 12;14(5):R216.

43-Gratacós J, Collado A, Filella X, Sanmartí R, Cañete J, Llena J, et al. (1994) Serum cytokines (IL-6, TNF-alpha, IL-1 beta and IFN-gamma) in ankylosing spondylitis: a close correlation between serum IL-6 and disease activity and severity. Br J Rheumatol. 33:927-31. 44-Gratacós J, Collado A, Pons F, Osaba M, Sanmartí R, Roqué M, et al (1999) Significant loss of bone mass in patients with early, active ankylosing spondylitis: a followup study. Arthritis Rheum. 42:2319-24.

45-Pacifici R. (1997) Idiopathic hypercalciuria and osteoporosis-distinct clinical manifestations of increased cytokine induces bone resorption? J Clin Endocrin ol Metab 82: 29-31.

46- Will R, Bhalla AK, Palmer R, Ring R, Calin A: (1989) Osteoporosis in early ankylosing spondylitis: a primary pathological event? Lancet II:1483-1485.

47- Oddsson A, Sulem P, Helgason H, Edvardsson VO, Thorleifsson G, Sveinbjörnsson G, et al. (2015) Common and rare variants associated with kidney stones and biochemical traits. Nat Commun. 14;6:7975.

48- Curhan GC, Willett WC, Rimm EB, Stampfer MJ (1997) Family history and risk of kidney stones. J Am Soc Nephrol. 8:1568-73.

49- Stechman MJ, Loh NY, Thakker RV. (2007) Genetics of hypercalciuric nephrolithiasis: renal stone disease. Ann N Y Acad Sci. 1116:461-84

50-Sayer JA. (2008) The genetics of nephrolithiasis. Nephron Exp Nephrol 110;e37-e43. 
51- Tsui FW, Tsui HW, Cheng EY, Stone M, Payne U, Reveille JD, et al. (2003) Novel genetic markers in the 5'-flanking region of ANKH are associated with ankylosing spondylitis. Arthritis Rheum. 48:791-7

52- Tsui HW, Inman RD, Paterson AD, Reveille JD, Tsui FW. ANKH variants associated with ankylosing spondylitis: gender differences. (2005) Arthritis Res Ther. 7(3):R513-25 53- Liu Z, Cui Y, Zhou X, Zhang X, Han J. (2013) Association of mineralization-related genes TNAP and ANKH polymorphisms with ankylosing spondylitis in the Chinese Han population. Biosci Trends. 7:89-92.

54- Korkmaz C, Sayer JA. (2012) ANKH and renal stone formation in ankylosing spondylitis. J Rheumatol 39:1756

55-Ho AM, Johnson MD, Kingsley DM. (2000) Role of the Mouse ank gene in control of tissue calcification and arthritis. Science 289:265-270.

56-Russell RG. (1976) Metabolism of inorganic pyrophoshate (PPi). Arthritis Rheum (Suppl 3):465-478.

57- Moochhala SH, Sayer JA, Carr G, Simmons NL. (2008) Renal calcium stones: insights from the control of bone mineralization. Exp Physiol. 93:43-9.

58- Carr G, Sayer JA, Simmons NL. (2007) Expression and localisation of the pyrophosphate transporter, ANK, in murine kidney cells. Cell Physiol Biochem. 20:507-16.

59- Pimentel-Santos FM, Ligeiro D, Matos M, Mourão AF, Vieira de Sousa E, Pinto P, et al. (2012) ANKH and susceptibility to and severity of ankylosing spondylitis. J

Rheumatol.;39(1):131-4.

60- Timms AE, Zhang Y, Bradbury L, Wordsworth BP, Brown MA. (2003) Investigation of the role of ANKH in ankylosing spondylitis. Arthritis Rheum. 48(10):2898-902.

61- Hess B. (1998) Drug-induced urolithiasis. Curr Opin Urol 8:331-334.

62-De Koninck AS, Groen LA, Maes H, Verstraete AG, Stove V, Delanghe JR. (2016)

Unusual Type of Kidney Stone. Clin Lab. 62:235-9.

63- Erturk E, Casemento JB, Guertin KR, Kende AS. (1994) Bilateral acetylsulfapyridine nephrolithiasis associated with chronic sulfasalazine therapy. J Urol. 151:1605-6.

64- Yanagisawa R, Kamijo T, Nagase Y. (1999) A case of drug induced urolithiasis composed of acetyl sulphapyridine associated with ulcerative colitis. Nihon Hinyokika Gakkai Zasshi. 90:462-5. (Japanese)

65- Russinko PJ, Agarwal S, Choi MJ, Kelty PJ. (2003) Obstructive nephropathy secondary to sulfasalazine calculi. Urology. 62(4):748. 
66- Hoffnung JM, Parker MD, Hartz JW. (1982) Papillary necrosis mimicking staghorn calculi Urology 20:325-7.

67-Boonen A, Everens JL. (2002) Ankylosing spondylitis: What is the cost to society and can it be reduced? Best Practise\&Research Clin Rheumatol 16:691-705.

68-Ben-Ami H, Ginesin Yİ Behar DM, Fischer D, Edoute Y, Lavy A. (2002) Diagnosis and treatment of urinary tract complication in Crohn's disease: An experience over 15years. Can J Gastroenterol 16:225-229.

69-Sato S, Sasaki I,Naito H, Funayama Y, Fukushima K, Shibata C et al. (1999) Management of urinary complications in Crohn's disease. Surg Today 29:713-717

70-Boussorra H, Sallami S, Said Y, Chebil M, Najjar T. (2013) Evaluation of urinary urolithiasis in Crohn's disease in Tunisian patients. Tunis Med 91:440-443.

71-Keddis MT, Rule AD. (2013) Nephrolithiasis and loss of kidney function. Curr Opin Nephrol Hypertens 22:390-396.

72-Vupputuri S, Soucie JM, McClellan W, Sandler DP. (2004) History of kidney stones as a possible risk factor for chronic kidney disease. Ann Epidemiol 14:222-228.

73-Akman T, Binbay M, Aslan R, et al. (2012) Long-term outcomes of percutaneous nephrolithotomy in 177 patients with chronic kidney disease: a single center experience. $\mathbf{J}$ Urol 187:173-177. 